\title{
Assessment of the Effects of Procurement Planning Processes on Performance of Construction Contracts in Local Governments in Uganda
}

\author{
Lawrence Muhwezi", Fred Tumusime Musiime, Charles Onyutha \\ Department of Civil and Building Engineering, Kyambogo University, Kampala, Uganda \\ Email address: \\ lmuhwezi@kyu.ac.ug (L. Muhwezi) \\ ${ }^{*}$ Corresponding author
}

\section{To cite this article:}

Lawrence Muhwezi, Fred Tumusime Musiime, Charles Onyutha. Assessment of the Effects of Procurement Planning Processes on Performance of Construction Contracts in Local Governments in Uganda. Journal of Civil, Construction and Environmental Engineering. Vol. 5, No. 6, 2020, pp. 151-160. doi: 10.11648/j.jccee.20200506.12

Received: August 25, 2020; Accepted: September 21, 2020; Published: December 11, 2020

\begin{abstract}
Procurement as one of the core functions of public sector agencies in Uganda has become a big matter of concern as expenditure on its processes have continued to be alarmingly high in government departments including local governments. This study assessed the effects of procurement processes on performance of construction contracts in Local Governments in Uganda. The study adopted a descriptive research design and used purposive sampling to sample 81 respondents. Data were collected using questionnaire and analyzed using SPSS software. The study revealed that poor procurement planning led to big budget deficits with a mean of 1.86 thus affecting performance of construction contracts to a very large extent. The study further revealed that funds for the construction contracts are not always released in time and this has a big effect on performance of construction contracts. The study concluded that procurement planning and contract monitoring and administration have a significant effect on the performance of construction contracts in District Local Governments in Uganda. The study recommended that Local Governments should adopt the developed model to control the procurement process and other anomalies in the award and management of construction contracts.
\end{abstract}

Keywords: Procurement Process, Local Governments, Framework, Contract Management, Performance

\section{Introduction}

In Uganda, Public Procurement and Disposal of Assets is handled by procurement disposal entities (PDEs) in accordance with the Public Procurement and Disposal Assets Act of 2003 [1, 2]. The Act specifies procurement guidelines and standards to all potential providers of goods, services and works [3]. In Uganda, poor procurement planning has led to non-compliance to the PPDA Act and guidelines [4-6]. Poor procurement planning in Uganda is characterized by failure to prepare adequate specifications leading to cost over runs and design reviews as well as onsite delays [7]. In their study, they identified the major determinants of deficiency in procurement contract management in Uganda as: lack of political will to monitor contracts; lack of capacity in contract management, monitoring of various stakeholders and lack of integrity in the contract management process [8]. The causes of poor performance of contract management in Uganda are evident in the PPDA Annual Procurement and Disposal Report [9] where i) 106 procurements worth UGX $27,254,851,330$ experienced delays, there was poor workmanship and the contractors abandoned the sites before contract completion; ii) 518 procurements worth UGX $50,786,805,589$ showed no evidence of appointment of contract supervisors and preparation of contract implementation plans, iii) 236 procurements worth UGX $25,055,153,118$ indicated that evaluation methodology and criteria stated in the solicitation documents was not adhered to and there was unfairness during evaluation leading to contract award to non-compliant bidders and compromises on benefits of maximum competition, iv) 195 procurements worth UGX $12,701,305,846$ entities failed to prepare solicitation documents and 68 procurements worth UGX 13,800,419,774 used wrong procurement methods. 
It was reported that in Sheema district, there was non-compliance in setting criteria per the Act, Regulations, and Guidelines and the Procurement Audit Manual. For instance, the compliance levels (which indicated unsatisfactory performance) for the Accounting Officer, Procurement and Disposal Unit, Contracts Committee, User Departments and Internal Controls were 56\%, 53\%, 55\%, $45 \%, 40 \%$, and $50 \%$, respectively. Poor procurement performance is a major hindrance to the growth of procuring since it causes the delay of delivery, cost overrun and increase of defects [10]. Studies have indicated that many procurement activities suffer from neglect, lack of direction, interference, poor co-ordination, lack of open competition and transparency, differing levels of corruption and most importantly not having a cadre of trained and qualified procurement specialists who are competent to conduct and manage such procurements in a professional, timely and cost effective manner $[11,12]$.

\subsection{Research Gap and AIM of the Study}

This study was sparked off by the poor contract performance revealed by the PPDA Annual Procurement and disposal Report of 2017 in which Sheema DLG was ranked $65^{\text {th }}$ with an overall score of 52.9 which was unsatisfactory according to this report. Sheema DLG was considered as a case study in order to enable the researcher establish the deficiencies in the procurement system and processes so as to enable management to devise strategies for the effective monitoring and appraisal of procurement performance of government agencies operating in the district on the guidance of statutory procurement recommendations and guidelines. Failure to establish the deficiencies in the system might spell doom for the construction activities in the district as the contracted companies might continue to bypass and ignore that statutory specifications spelt out in the PPDA Act, thereby leading to shoddy works, noncompliance and untimely delivery of construction contracts.

Based on the above highlights, therefore, the aim of this study was to assess the procurement processes in Local Governments in Uganda to establish the missing links and how they impact on the performance of construction contracts.

\subsection{Significance of the Study}

Performance of construction contracts in local governments especially procurement related issues have not been widely researched in Uganda. Despite the continued outcry of poor performance of construction contracts in terms of completion, payment and quality of works, there is limited information about the causes of the poor performance and more so in relation to procurement processes. This study, therefore, will add extensive information to the existing limited knowledge on the effect of procurement process on performance of construction contracts in local governments in Uganda. The findings of this study will compel project practitioners involved in procurement related activities and policy makers to take proactive measures to improve construction contract performance in local governments in terms of cost, quality and timeliness which will improve service delivery to all project beneficiaries.

\section{Literature Review}

Government procurement activities beginning with procurement planning tend to deliberately disown competition by providing information to some providers and withholding it for others in exchange of material gifts for civil servants to maximize their own utility [13]. The large amounts of funds spent through procurement and the high levels of discretion and bureaucracy often involved in such processes provide incentives and opportunities for the rent seeking behavior. Incompetent contractors end up being contracted leading to poor quality work.

Poor procurement planning in Uganda was pointed out as an indicator of corruption in public procurement [14]. This makes the government sectors vulnerable to corruption. In a conducted study in Uganda on developing public procurement performance measurement systems in developing countries the authors noted that proper planning has an influence on procurement performance [15]. In his study on the factors affecting procurement performance of Ministry of Energy in Kenya, it was noted that planning is the process of choosing the most appropriate contractor to deliver a specified project so that there is achievement of best value for money [16]. Procurement methods are one of the critical steps in planning and bid evaluation methods are the key procedures through which a contractor is selected. Planning is one of the main decisions made by the clients. In order to ensure that the project can be completed successfully, the client must select the most appropriate contractor [16].

Procurement is divided into a number of processes which are clearly distinct [17]. The processes are at initiation, intermediate and execution levels. At initiation level one has to plan basing on the needs, assess availability of resources and budget for the needs then clearly state what goal of the organization the deliverables will be able to fulfill or contribute in order to be more meaningful. Therefore, a professional procurement process can be incredibly beneficial if one is aiming at streamlining purchasing. It can ensure that one pays the best price for goods or services, save time by choosing the most reputable vendors, and minimize order delays and mistakes [18].

The process of procurement does not end at the selection of service providers but rather continues up to point of delivery and also goes up to when retention period is finalized [19]. It is the work of the procurement departments to schedule the construction works as part of the terms of reference for the service providers to ensure deliverables are timely, involve as many stakeholders as possible and puts in place mechanisms for quality assurance including monitoring and evaluation [18]. Construction contracts performance is associated with timely deliverables, quality outputs that meet expectations of the clientele [20]. In this study the researcher studied the ways in which the procurement processes are related to the performance of construction contracts. 


\subsection{Procurement Planning}

Procurement planning is a process whereby procurement practitioners sketch out in advance an arrangement with a diagram plan as to what, which, when and how purchases are to be conducted in a given period [21]. Study findings have indicated that one of the major setbacks in public procurement is poor procurement planning and management of the procurement process which include needs that are not well identified and estimated, unrealistic budgets and inadequacy of skills of procurement staff responsible for procurement and this leads to shoddy works and delays in construction contracts [22].

The legal requirements that guide public entities in planning have to be adhered to as defined in section 58 of [23]. The planning function encompasses defining an organization's goals, establishing an overall strategy for achieving those goals and developing a comprehensive hierarchy of plans to integrate and coordinate the activities.

Procurement planning provides a framework for the execution of the requirement and user departments usually expect their requirements to be delivered within the shortest time possible. Within the budget confines, user departments would normally choose a procurement method which achieves their immediate expectations than the legally acceptable procurement method. Procurement needs are normally initiated late leading to late implementation of projects [24, 25]. It's a procurement strategy that is done at a procurement planning stage and it's an important factor of production. Thus, without respecting time, procurement activities are currently faced with problems of delays that is normally brought about by poor procurement planning.

It is important to establish the delivery schedules in line with the contractual obligations and that this is done at the procurement planning stage [26]. Costs and deadlines need to be respected in order to act as a control measure. Procurement processes require timely completion of the project [27]. Despite this standard, most entities in Uganda accumulate arrears as a result of poor procurement planning. Unplanned activities normally lead to spending outside the budget [23]. All the expectations of stakeholders need to be studied and assessed so that they are feasible and implementable by the procurement units. The legal requirements that guide public entities in planning have to be adhered to in Uganda under section 58 of the PPDA Act amended [22].

A study conducted in Uganda on developing public procurement performance measurement systems in developing countries established that the key to accountability is the capacity to select the best contractors within the public sector [15]. The internal contractor selection process of government, procurement and personnel have long received sustained attention as the centerpiece of reforms to promote accountability. Tendering is a procurement method that limits the request for tenders to a select number of contractors [28, 29]. Restricted procurement method is a two-stage process where the employer advertises his project and invites contractors to express interest to be placed on a selected list of contractors who will be invited to bid for the project [23].

\subsection{Contract Monitoring and Administration and Its Effect on the Performance of Construction Contracts}

Contract monitoring and administration aims at ensuring enforcement of contract terms while giving attention to achievement of stated output and outcome of the contract [30]. According to agency theory, the divergence of interests between principal and agent can be mitigated by instituting proper contract management procedures and by monitoring activities to limit opportunistic actions which are aspects of inter-functional coordination.

Contract monitoring is a process of ensuring that a vendor adequately performs a contracted service [31]. Key suppliers of high value and high risk goods and services require close performance and relationship monitoring and this is where most resources should be employed. This may well involve monthly meetings where performance is discussed, issues resolved and new targets set as appropriate. Key supplier failure can bring significant losses to a business, and therefore it is important to ensure that the contract contains suitably robust exit clauses and contingency plans [31].

In the event that the monitoring process is managed outside the Procurement and Supply Management (P\&SM) function, it is essential to ensure the staff have sufficient authority and training to enable them to carry out their role. It is of critical importance that whoever carries out performance monitoring has the correct skills and the full support of the (P\&SM) function. This is particularly important when the payment mechanism in the contractual arrangement is contingent on supplier performance measures. This recommendation presupposes that staff of an organization like Sheema DLG should engage in capacity building in order to enable her staff acquire the competences of handling the associated activities.

In his study findings and recommendation on contract management, KPIs do not measure all of the critical elements of the service, or do not reflect areas of known service deficiency. There are uncertainties over accuracy of some reported KPIs and uncertainties over the suppliers' interpretations of the intent of some KPIs. The report suggested that a contracting firm should design KPIs and data requirements which adequately measure and reflect the benefits the contract is intended to deliver. A performance management review process should be carried out at regular intervals for all contracts in order to ensure that KPIs remain relevant and deliver measures of contract benefits. KPIs must be designed to be fair and balanced. The report stressed the need of proper KPI and having a staffed and competent contract management team [32]. However, the recommendations were made in the context of oil projects and in developed countries, thus leaving a gap for project performance in Local Government units in developing countries such as Uganda.

Monitoring and evaluation is central to the project control process. Many times, actual progress does not match the planned progress making it essential to keep the management, client, engineer and sponsor informed of the progress and the 
precise conditions that can affect each occurrence. So, depending upon the extent of variation between planned and actual, the management should initiate appropriate control actions. Similar views are held that most information is analyzed by variance i.e. difference between planned and actual performance and it is management which will determine what is useful in analyzing individual situation [33].

\section{Methodology}

The study adopted a descriptive survey design which is easy to manage and administer [34]. The design enables the study to quickly collect data from an extensive area and to understand the entire population from a sample [35]. The study sample that was purposively selected constituted 15 pre-qualified contractors for Sheema District for a period of 4 years i.e. from 2015 to 2019, 10 district management committee members, 25 evaluation committee members, 5 members of contracts committee, 20 technical planning committee members, 5 district executive committee members.

Data were collected using a self-administered questionnaire, interview guide and document analysis. The questionnaire was selected as the main data collection tool because it is cheap to administer and covers a wide geographical area; it provides a hard copy that can be filed for reference purposes. To ensure reliability of data that were used, the questionnaire was first pretested and a content validity index (CVI) value of 0.97 was obtained implying a reliable questionnaire was used for data collection [36]. Interview guides were also administered to the top district management for in-depth data collection.

Data were analyzed at univariate and bivariate levels. Univariate analysis involved use of the Relative Importance Index (RII) while bivariate analysis involved use of linear regression analysis in which a mathematical model was developed.

\section{Results and Discussion}

\subsection{Response Rate}

Response rate is an important factor in determining the quality of a study [37]. Table 1 shows that the overall response rate obtained was $94 \%$. The high response rate implies that the study findings represent views and opinions of a large number of the targeted respondents and can therefore draw generalizations on the scope and status on the procurement processes in the local governments and how this has influenced the performance of construction contracts.

Table 1. Response rate by category of respondents.

\begin{tabular}{llll}
\hline Category & Number targeted & Actual number participated & Response rate (\%) \\
\hline Pre-qualified Contractors since 2014-2019 & 15 & 14 & 100 \\
Contracts committee & 5 & 5 & 100 \\
Technical Planning committee & 26 & 24 & 77 \\
District Executive committee & 5 & 5 & 100 \\
District management committee & 10 & 10 & 100 \\
Evaluation committee members & 25 & 23 & 87 \\
Overall response rate & 86 & 81 & 94 \\
\hline
\end{tabular}

Source: Primary Data, 2019.

\subsection{Level of Education of the Respondents}

Figure 1 indicates that the respondents with certificate and below were $5(6 \%)$, diploma holders were $16(20 \%)$, degree holders were $53(65 \%)$ and those with master's degree were 7 $(9 \%)$.

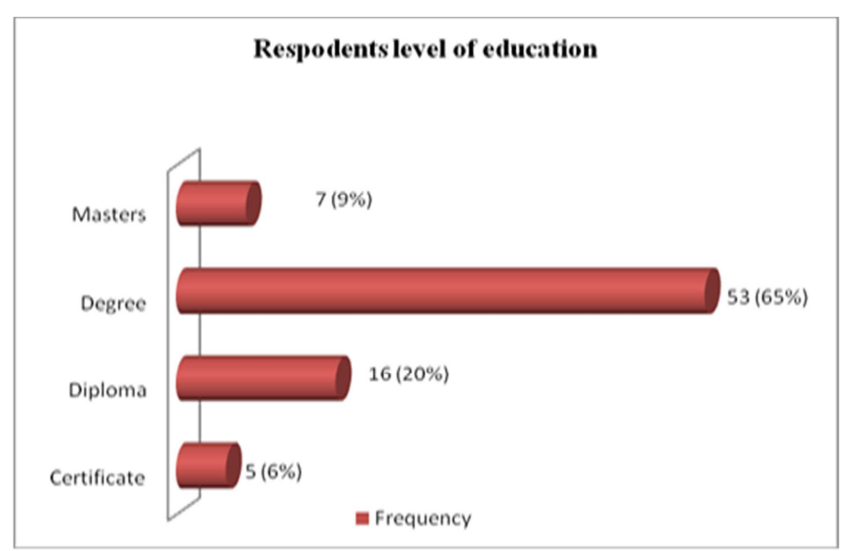

Figure 1. Description of respondents by level of education.
The different levels of academic qualifications indicated a mixed category of respondents who participated in providing data for this study. By implication, the study findings are informative largely because they captured the views of the respondents from different academic segments.

\subsection{Working Experience of the Respondents}

Table 2. Working Experience.

\begin{tabular}{lll}
\hline Responses & Frequency & Percent \\
\hline Less than 1 year & 7 & 9 \\
1 - 3 years & 9 & 11 \\
4 - 6 years & 15 & 19 \\
7 - 9 years & 36 & 44 \\
10 years and above & 14 & 17 \\
Total & 81 & 100 \\
\hline
\end{tabular}

Source: Primary Data (2019).

The respondents were asked to indicate the number of years they had worked in their capacities and designations. The results in Table 2 indicate that $80 \%$ of the respondents had served for more than 4 years. 
This finding implies that majority of the respondents had experience in matters related to procurement processes and performance of the contracted construction projects. The findings of the study therefore are credible and reliable because they were obtained using information from experienced respondents in the area of study.

\subsection{Performance of Construction Contracts}

\subsubsection{Descriptive Statistics on Performance of Construction Contracts}

The respondents were requested to indicate their opinion on the variables that measured performance of construction contracts. Construction contracts performance in Sheema DLG was assessed using five questions as shown in Table 3. The results indicate that respondents disagreed that: construction contracts were usually completed under the budgeted costs and at the best minimum (Mean=2.44, St. Dev=1.38); construction contracts in Sheema DLG met the organization's contractual scope $($ Mean=2.39, St. Dev=1.38); construction contracts in Sheema DLG were usually completed on time (Mean=2.32, St. Dev=1.46) respectively.

The cost overruns and delayed completion of projects were symptoms of poor performance construction contracts in Sheema DLG. Cost and schedule performance are the primary measures of a project's success. A contracted project is said to be successful if it is completed within the planned cost and time. The accuracy of cost estimates starting from the planning phase of a project through to the tender estimate can affect the success or failure of a construction project. These findings are in line with similar study which indicated that the project manager is responsible and accountable for setting realistic and achievable boundaries for the project and to accomplish the project within the approved baselines [38]. The same study asserted that time overruns always proved expensive to all parties and has adverse effects on project success in terms of time, cost and quality.

Table 3. Descriptive statistics on performance of Construction contracts.

\begin{tabular}{|c|c|c|c|c|c|}
\hline $\mathbf{S} / \mathbf{N}$ & Performance of construction contracts aspects & Mean & StDv & RII & Ranking \\
\hline 1. & Sheema DLG construction contracts are usually completed at minimum possible cost & 2.444 & 1.38 & 0.489 & $1^{\text {st }}$ \\
\hline 2. & Sheema DLG construction contracts usually meet the District's contractual scope & 2.395 & 1.38 & 0.479 & $2^{\text {nd }}$ \\
\hline 3. & Sheema DLG construction contracts are usually completed on time & 2.321 & 1.34 & 0.464 & $3^{\text {rd }}$ \\
\hline 5. & Sheema DLG construction contracts usually produce quality deliverables all the time. & 1.568 & 1.21 & 0.314 & $5^{\text {th }}$ \\
\hline
\end{tabular}

Key: 1.00-2.99=Disagreed, 3.00=Not Sure, 3.01-5.00=Agreed.

Table 3 equally indicates that respondents disagreed that Sheema DLG always registered a higher level of beneficiary satisfaction with the construction contracts (Mean=2.09, St. Dev=1.37). Failure to meet the contractual scope of Sheema DLG by the contractors meant that quality was compromised. The implication of this finding is that there is absence of a quality plan. In order to manage quality, there must be a quality plan that spells out how the quality performance and objectives will be achieved. In the case of construction projects, the quality plan specifically provides details on how the quality function is organized, who are the responsible individuals, and the quality control checks i.e. inspection and testing. The deviations in quality implies less than optimal performance which compromised the levels of beneficiary satisfaction. These study findings meant that much as the respondents agreed that the construction contracts in Sheema DLG benefitted a wide scope of beneficiaries, the key parameters used in assessing the performance of these projects indicated that they were performing poorly.

\subsubsection{Effect of Procurement Planning on the Performance of Construction Contracts}

In this section, mean was used in the analysis and interpretation of the findings in order to give opinions of the respondents on each variable in Table 4. The Relative Importance Index (RII) was employed to show the extent to which the selected aspects measuring procurement planning were being practiced by management of Sheema DLG. The study findings indicate that majority of the respondents disagreed that management formulated a contingency plan to handle crises (Mean=2.35, St. Dev=1.57). Contingency planning is a necessary component of the overall contract planning and administration that is often overlooked by agencies. It addresses how the agency would respond in the event of an interruption of service delivery. Contingency planning allows the program or service to be quickly resumed. In Sheema DLG, the respondents disagreed that there existed a contingency plan for handling crises arising from contracted projects. This affected the quality of the construction projects.

Table 4 also indicates that respondents (Mean=2.29, St. Dev=1.37), disagreed that Sheema DLG prepared compliance checklists for construction contracts most of the time. Due to the volume, number and complexity of the transactions involved, procurement is one of the government activities most vulnerable to corruption. Availability of procurement compliance checklists in a government entity such as Sheema DLG is an important element of corruption risk management strategies in procurement processes, both in terms of prevention and detection of fraud and corruption as they guide procurement staff through the process of transparent and effective procurement and in the detection and reporting of irregularities. In this line of argument, the management of Sheema DLG would realize the set performance goals of the construction contracts if they prepare compliance checklists for the contracted projects. Further, the district can realize improved levels of construction project performance if the compliance checklists are structured around the major phases of the procurement cycle and typically covering the various 
risks associated with each phase of the contracting process. On whether all stakeholders were involved in procurement planning in Sheema DLG, findings indicate that some respondents disagreed (Mean=2.19, St Dev=1.51). Key stakeholders in construction projects include customers, subcontractors, suppliers and sometimes even the government.

The project manager, project team members, and the managers from other departments in the organization are stakeholders as well. It's important to identify all the stakeholders in the project upfront. Through informal conversations with the respondents, it was established that some of these stakeholders have often been left out of procurement planning meetings at the district and yet they are important stakeholders or their department's function. This has negatively impacted performance of construction contracts.

Table 4. Description of aspects of procurement planning.

\begin{tabular}{|c|c|c|c|c|c|}
\hline S/No & Procurement planning aspects & Mean & Std. Dev & RII & Ranking \\
\hline 1. & Contingency plans are developed to handle contractor's failure and exit by management. & 2.35 & 1.57 & 0.538 & $1^{\text {st }}$ \\
\hline 2. & Sheema DLG prepares procurement compliance checklists for construction contracts & 2.29 & 1.37 & 0.523 & $2^{\text {nd }}$ \\
\hline 3. & Procurement planning meetings involve all stakeholders. & 2.19 & 1.51 & 0.506 & $3^{\text {rd }}$ \\
\hline 4. & Sheema DLG always develops Key Performance Indicators (KPIs) for every construction contracted & 2.15 & 1.38 & 0.479 & $4^{\text {th }}$ \\
\hline 5. & Sheema DLG prepares ToRs and SoWs in time & 2.12 & 1.46 & 0.417 & $5^{\text {th }}$ \\
\hline 6. & $\begin{array}{l}\text { Both operational and management controls are put in place to control the effective and efficient } \\
\text { performance of construction contracts. }\end{array}$ & 2.08 & 1.36 & 0.385 & $6^{\text {th }}$ \\
\hline
\end{tabular}

Key: 1.00-2.99=Disagreed, 3.00=Not Sure, 3.01-5.00=Agreed

Source: Primary Data.

Item 4 shows that respondents $($ Mean=2.15, St. Dev=1.38) disagreed that Sheema DLG prepared Key Performance Indicators (KPI) for every construction project contracted. In order to realize the construction project goal, KPIs are supposed to be prepared by the contracting organization or institution according to milestones and accountabilities set in the procurement plan. KPIs are critical for the successful implementation of project activities because they keep the project objectives at the forefront of decision making.

The study findings in Table 4 further indicate that all the respondents disagreed to the statements on procurement planning activities in Sheema DLG implying that procurement planning activities were not favorable largely because most respondents disagreed while others were undecided. It is shown in Table 4 that the respondents disagreed that all the necessary pre-contract documentation are always prepared in time (Mean=2.12, St. Dev=1.46). Among the documents investigated by the study were: Terms of reference (TOR) and Statement of Work (SoW). The ToR is important and should be prepared in time because it defines the purpose and structures of a project, committee, meeting, negotiation, or any similar collection of people who have agreed to work together to accomplish a shared goal. ToRs further provide information regarding the aims of the Contracting Authority in connection with the implementation of the contract. This information should be presented with an appropriate level of detail and with appropriate clarity, in order to allow: candidate economic operators to form a clear picture of the reasons for which the contract is implemented, ascertain its importance and understand fully what they are expected to deliver and achieve, if they are awarded the contract.

\subsubsection{Effect of Contract Monitoring and Administration on the Performance of Construction Contracts}

The respondents were asked their opinion concerning the various attributes of contract monitoring and administration to determine how it affected the performance of construction contracts in Sheema DLG and their opinions are presented in
Table 5. Findings indicate that majority of the respondents disagreed that Sheema DLG procurement department often conducts pre-performance meetings (Mean=2.69, St. $\mathrm{Dev}=1.46$ ) yet these are necessary to clarify the procedures to be used throughout the contract term and as well enable all parties to better understand one another's expectations. In the management of a construction contract, such meetings are ideal and necessary because the members of the contract administration team may have different views of the contract due to their different responsibilities. The meetings are important in a way because they enhance the harmonization of the conflicting views as well as enabling the team members to embrace team effort.

Results indicated that respondents disagreed that Sheema DLG carried out comprehensive follow up monitoring of the construction contracts (Mean=2.51, St. Dev=1.56). Follow-up monitoring is the inspection method that aids in the provision of answers to general and specific questions such as: Does the work meet contract requirements? Is the contractor on schedule? Have the required number of units of service been delivered? Are clients satisfied with the service? Has the work area been left in acceptable condition? Is the construction rhyming with the approved plan? Are the construction materials used bought from the prequalified firms?

The failure of management of Sheema DLG to carry out follow up monitoring has compromised the quality of the construction projects as the above key questions are left unanswered. What can be understood from this scenario is that quite often, the construction projects upon completion, deviate from the standards set at the award of the contract. Findings further indicate that respondents were ambivalent on whether construction project performance was assessed on a quarterly basis using clear, objective and meaningful indicators (Mean=2.35, St. Dev=1.37). In essence, this finding implies that assessment of the construction was done on a quarterly basis, however, the indicators used seemed to lack clarity, were not objectively pinned to the scope of the contracted 
project and equally lacked breadth to cover all the aspects of the construction project comprehensively. In one way or the other, this resulted into poor performance of the construction projects. In principle, the quarterly reports assuming they covered all the construction projects would help to provide corrective means of ironing out the deficiencies in the projects.

Regarding the cross checking of contractor performance, Table 5 indicates that the respondents disagreed that contractor performance is cross checked with preset sound metrics monthly (Mean=2.34, St. $\mathrm{Dev}=0.62)$ while Item 8 shows that the respondents disagreed that acceptable performance measures were used to appraise performance of contractors $(\mathrm{Mean}=2.53$, St. Dev=1.22). From these findings, the chances are high that most of the construction projects in Sheema DLG do not meet the standards of a quality construction as assessments and checks are not standardized and regularly done. Through informal conversation with the District Engineer, it was established that some construction have honey comb, are constructed inferior construction materials and have poor quality concrete. On the road sections, most develop depression like potholes while many others at large are susceptible to rutting. This has led to poor performance of the construction projects. On whether accurate and timely monitoring reports were prepared for management for purposes of improving on the performance of the construction projects, Table 5 indicates that majority of the respondents disagreed that accurate and timely the reports were prepared $(\mathrm{Mean}=1.24$, St. Dev=0.43). With regard to monitoring of startups, Table 5 indicates that majority of the respondents disagreed that Sheema DLG carries out monitoring at the startup period of the construction contracts $($ Mean=2.11, St. Dev. $=1.38)$.

Table 5. Description of aspects of contract monitoring and administration.

\begin{tabular}{|c|c|c|c|c|c|}
\hline No & Aspects of contract monitoring and administration & Mean & Std. Dev & RII & Ranking \\
\hline 1 & Sheema DLG contracts management team often holds pre-performance meetings. & 2.69 & 1.46 & 0.538 & $1^{\text {st }}$ \\
\hline 2 & Acceptable performance measures are used to appraise performance of contractors. & 2.53 & 1.22 & 0.506 & $2^{\text {nd }}$ \\
\hline 3 & Sheema DLG conducts follow up monitoring of all construction contracts. & 2.51 & 1.61 & 0.504 & $3^{\text {rd }}$ \\
\hline 4 & $\begin{array}{l}\text { Project performance in Sheema DLG on a quarterly basis using clear, objective and } \\
\text { meaningful indicators. }\end{array}$ & 2.35 & 1.37 & 0.472 & $4^{\text {th }}$ \\
\hline 5 & Contractor performance is cross checked with preset sound metrics monthly. & 2.34 & .62 & 0.469 & $5^{\text {th }}$ \\
\hline 6 & $\begin{array}{l}\text { Contract manager understands his/her role and has clear visibility of well-structured } \\
\text { roles/responsibilities on the contractor's side. }\end{array}$ & 2.23 & 1.38 & 0.447 & $6^{\text {th }}$ \\
\hline 7 & Contract manager is appointed for each contracted project & 2.21 & 1.42 & 0.435 & $7^{\text {th }}$ \\
\hline 8 & Monitoring reports produced focus on variances & 2.17 & 1.47 & 0.435 & $8^{\text {th }}$ \\
\hline 9 & Sheema DLG carries out monitoring at the beginning of construction projects. & 2.11 & 1.38 & 0.422 & $9^{\text {th }}$ \\
\hline 10 & Accurate and timely monitoring reports are prepared for management. & 1.24 & .43 & 0.249 & $10^{\text {th }}$ \\
\hline
\end{tabular}

Key: 1.00-2.99=Disagreed, 3.00=Not Sure, 3.01-5.00=Agreed.

Source: Primary Data.

It was established that limited efforts were made by the DLG management to monitor the construction contracted projects startups. Research indicates that even an experienced contractor sometimes underestimates the effort required to perform some aspects of the service and overestimates others. These miscalculations may cause performance to be uneven until the contractor makes the necessary adjustments in personnel and equipment to balance service in all contract areas. He recommends that during the start-up period, the contract administration team needs to monitor intensively but leniently in order to ably help the contractor get on the right path [39]. The situation in Sheema DLG deviates from the above standards hence providing antecedents of poor contract performance.

\subsection{Validation of Study Findings}

In order to validate the study findings, a stepwise multiple regression analysis was conducted in SPSS using input variables as: procurement planning (ProcPlan), contract monitoring and administration (ContMonAdm) and performance of the construction contracts (PerfConsContr). The results are summarized in Table 6.

Table 6. Summary Multivariate Model.

\begin{tabular}{|c|c|c|c|c|c|}
\hline & Sum of squares & Df & Mean Square & $\mathbf{F}$ & p-value \\
\hline Regression & .541 & 3 & .180 & 4.344 & .037 \\
\hline Residual & 9.115 & 68 & .134 & & \\
\hline Total & 9.656 & 71 & & & \\
\hline
\end{tabular}

$\mathrm{p} \leq 0.05$.

The results from table 5 show that there is a positive significant relationship between procurement planning, contract monitoring and administration and performance of construction contracts in Sheema DLG $(\mathrm{p}<0.05)$. The magnitude of the effect of the procurement processes on the performance of construction contracts is shown in Table 7. 
Table 7. Regression Model Coefficients.

\begin{tabular}{lllll}
\hline Variables & Coefficients std. Error & Standard coefficients & t-statistic & P-value \\
\hline Performance & .311 & & 3.772 & 0.000 \\
Procurement planning & .113 & .128 & 4.071 & 0.028 \\
Contract monitoring and administration & .625 & .051 & 2.424 & 0.043 \\
\hline
\end{tabular}

From Table 7 above, the resulting regression model is represented by equation 1 .

$$
\mathrm{Y}=0.311+0.113 \mathrm{X}_{1}+0.625 \mathrm{X}_{2}+\varepsilon \ldots
$$

\section{Where: $Y=$ Performance}

$\mathrm{X}_{1}=$ Procurement planning

$\mathrm{X}_{2}=$ Contract monitoring and Administration

$\varepsilon=$ Error term

The results show that there is positive significant relationship between procurement planning and the performance of construction contracts at 0.05 level of confidence $(p=0.028<0.05)$. The model also shows that a unit increase in procurement planning leads to $11.3 \%$ improvement in the performance of construction contracts. This observation provides a clear testimony that procurement planning should be considered a core and key activity in the procurement process [40]. The study further argues that in case an entity fails to carry out effective procurement planning, the procurement/resulting contract can be marred by dissatisfaction among the beneficiaries. As well, this could lead to wastage of time and resources as the corrective function of planning is lost. It is recommended that contracting entities ought to formulate a fully-fledged procurement plan that among others, helps to describe describing the processes that the contracting institution will you will go through to appoint those suppliers contractually [40].

The findings of the study are amplified by similar study which established that procurement planning is very important because it provides the list of all requirements that an entity would procure over a period of time [41]. It enumerates the contributions of the procurement planning further by enlisting that from the same, the procurement schedules are developed and the timelines for carrying out each step in the procurement process up to contract award and the fulfillment of the requirements are established. Furthermore, the resulting procurement plan allows for the consolidation of similar requirements under one contract or the division of a requirement into several contract packages for economies of scale and equally enables the procuring entity to forecast any need for additional inputs; allows for the monitoring of the procurement process to determine how actual performance compares with planned activities; and enhances transparency and predictability of the procurement process.

The results further indicate that there is positive significant relationship between contract monitoring and administration and the performance of construction contracts at $5 \%$ level of confidence $(p=0.043<0.05)$. The model also shows a unit increase contract monitoring and administration leads to a 62.5 percent improvement in the performance of construction contracts. The findings of the study are in agreement with those of other researchers who observed that performance of contracted projects is a function of the effective monitoring and administration which is suggestive that the entire procurement team should also be engaged in managing the post award contracting activities $[42,43]$. To effectively carry out contract monitoring and administration, the above scholars recommend that the management of the contracting institutions should endeavor to integrate administration processes and activities such as managing contractor payment process and managing contract change process with other departmental core processes such as risk management department.

The findings concur with those of similar study which established that contracting firms or organizations should endeavor to monitor the contracted firms with regard to safely and timely delivery of the service for success of the project. The study considers monitoring and administration of contracts as a litmus for steering a project to the anticipated levels of performance [44].

\section{Conclusions and Recommendations}

\subsection{Conclusions}

From the findings of the study, it was concluded that procurement planning greatly affects the performance of construction contracts. It was also found out that poor performance of the construction contracts has been as a result of resource allocation, big budget deficits and procurement requirements definitions. The respondents disagreed to all the statements measuring contract monitoring and administration. Given this spate of deficiencies, it was concluded that contract monitoring and administration are vital elements in the performance of construction contracts.

\subsection{Recommendations}

Local governments should implement the frame work developed to control and eliminate corruption within the procurement process. Thus, this will help to avoid any deviations within the procurement process. Local governments should also endeavor to fulfill all the requirements and obligations of a contract; clauses, conditions, commitments and milestones that need to be tracked and managed hence be able to control costs.

Local government should recruit more qualified personnel to take control over procurement of contracts rather than solely leaving the control to one person (project manager). Local governments should endeavor to give the contractors enough time to execute the contracts and plan the procurement in time and also include the procurement contract management plan in the preliminary planning of the 
procurements such that contractors' performance can be enhanced.

\section{References}

[1] Colnelli, E., and Ntungire, N. (2018). Construction and Public Procurement in Uganda. Wider Working Paper 2018-180.

[2] Kakwezi, P., \& Nyeko, S. (2019). Procure ment processes and performance: Efficiency and effectiveness of the procurement func tion. International Journal of Social Sciences Management and Entrepreneurship, 3 (1).

[3] Government of Uganda (2003). The Public Procurement and Disposal of Public Assets Act, 1, 2003. [Online]. Available at www.ppda.go.ug.

[4] Masaba, A. K. (2010). Contracting, transacttion costs, behavioural practices and procurement performance of public entities: The case of state owned enterprises in Uganda (Doctoral dissertation, Makerere University).

[5] Okok, S. (2018). Addressing corruption in the public service: A virtue ethical critique of Uganda's integrity system (Doctoral dissertation, Makerere University).

[6] Mwelu N, Rulangaranga D. M, Watundu S, Tindiwensi K (2014). Lean Manufacturing and Profitability of Manufacturing Firms in Uganda. European Journal of Business and Management 6 (18): 187-190.

[7] Muhakanizi, K. (2015). The state of Public Service Delivery in Uganda, Achievements, Challenges and Measures for better service Delivery, National Budget Conference, Serena International Conference Centre, Kampala, Uganda.

[8] Oluka, P. N. and Basheka, B. C., (2014). De terminants and constraints to effective procurement contract management in Uganda, a practitioner's perspective. International Journal of Logistics Systems and Management, 17 (1), pp. 104-24.

[9] PPDA (2017). Annual Performance Report for Procurements and Disposals for the Year Ended June 2018.

[10] Murray, J. (2009). Improving the validity of public procurement research. International Journal of Public Sector Management. 22. 91-103.10.1108/09513550910934501.

[11] Awanyo, C. (2019). Procurement Planning and Service Delivery in Local Government: a case study of Lira District and Municipality (Doctoral dissertation, Uganda Christian University).

[12] Shanmugaraja, M., Nataraj, M. and Gunasekaran, N., (2013). Total performance excellence-a model for successful implementation of Six Sigma.

[13] Hao. X \& Qi. P (2011). Analysis on corrupttion and collusive behaviors in government procurement in a game theory perspective. Journal of management and strategy, 2 (2), 38. Doi: 10-5430/jms.v2n2p38.

[14] Transparency International (2013). Integrity Pacts in Public Procurement; An implementation guide. https://issuu.com/transparencyinternational/docs/2013integrity pactguideen/113.

[15] Sabiti, K. Muhumuza, E. and. Basheka, C. (2010). Developing Public Procurement Performance Measurement Systems in Developing Countries: The Uganda Experience.
[16] Kiage, J. O. (2013). Factors Affecting Procurement Performance: A Case of Ministry of Energy, International Journal of Business and Commerce, 3 (1), pp. 54-70.

[17] Attarzadeh, I., \& Ow, S. H. (2008). Project management practices: the criteria for success or failure. Communications of the IBIMA, 1, 234-241.

[18] Weiss, J., \& Potts, D. (Eds.). (2012). Current issues in project analysis for development. Edward Elgar Publishing.

[19] Aibinu, A. and Jagboro, G. (2002). The Ef fects of Construction Delays on Project Delivery in Nigerian Construction Industry. International Journal of Project Management, 20, 593-599. http://dx.doi.org/10.1016/S0263-7863(02)00028-5.

[20] Othman, E., \& Ahmed, A. (2013). Challenges of mega construction projects in developing countries. Organization, Technology \& Management in Construction: An International Journal 5 (1), 730-746.

[21] Rono, P. K. (2015). Determinants of Electronic Banking and operational Performance of Commercial Banks in Kenya. Doctoral Dissertation, University of Nairobi.

[22] Mamiro, R. G. (2010). Value for Money, The Limping Pillar in Public Procurement. Tanzania Procurement Journal, 4-5.

[23] PPDA (2014). Procurement and Disposal Audit Report on 74 Entities for Procurements and Disposals for the Year Ended June 2014; Local Government Entities Volume III.

[24] Lynch, J. (2013). Public Procurement, Principles, Categories and Methods, Vol. 2, Maidstone, United Kingdom, Lean Publishing.

[25] Guyana, R. (2010). Procurement Planning Manual 1st edition, Trinadad and Tobago.

[26] Kuuse, A. (2014). Project Procurement Management: Four smart steps for success. San Francisco: USA. Delta Bid Inc.

[27] Mwanje, J. (2016), Implications of Poor Procurement Planning in the Public Sector (A case Study of The Office of the Prime Minister, Uganda), MBA. Dissertation- Makerere University-Uganda.

[28] World Bank (2000), Poverty Reduction and Economic Management (PREM) Network.

[29] Oluka, P. N. (2013) "Public Procurement Reforms: Issues and Challenges: The case of Uganda" Presentation at the CIPS Pan African Conference 21-22 at National Theatre, Ghana.

[30] Davison, B. and Sebastian, R. (2009). The relationship between contract administration problems and contract type, Journal of public procurement, 9 (2), pp. 262-286.

[31] Chartered Institute of Procurement \& Supply (2013), Monitoring the Performance of Suppliers.

[32] Breedon, T., (2013). Contract management review, findings and recommendation report, Ministry of Justice. Retrieved on 20th November 2019 from https://www.gov.uk/government/uploads/system/uploads/attac hmentdata/file/267693/contractmanagement-review.pdf.

[33] Aitken, A and Crawford, L. (2007). "Coping with stress: Dispositional coping strategies of project managers" International Journal of Project Management 25, 7. 
[34] Mugenda, O. M. and Mugenda, A., G. (2003). Research methods.

[35] Kothari, C. R., (2003). Research Methodology: Methods and Techniques New Delhi: Wishwa Prakashan.

[36] Amin, M. E., (2005). Social science research: Conception, methodology and analysis. Makerere University.

[37] Krishnan, T. N., \& Poulose, S. (2016). Response rate in industrial surveys conducted in India: Trends and implications. IIMB Management Review, 28 (2), pp. 88-97

[38] Project Management Institute (2013). A Guide to the Project Management Body of Knowledge (PMBOK Guide), 5th Ed.

[39] Ashwini, A. S., and Rahul, S. P. (2014) Effect of construction delays on project time overrun: Indian scenario, International Journal of Research in Engineering and Technology 3 (1), 543-544.
[40] Ombui, R. G. (2018). Competitive forces influencing business performance of new vehicle companies in Nairobi, Kenya.

[41] Asakeya, G. K. (2014). Impact of procurement planning within Ghana Health services: A study of Ridge Hospital. Accra: Kwame Nkrumah University of Science and Technology.

[42] Bautista, R. O., \& Ward, C. R. (2009). Analysis of Contract Management Processes at Fleet \& Industrial Supply Centers (FISC) Worldwide. MBA Professional Report, Naval Postgraduate School, Monterey, CA.

[43] Hotterbekx, S. G., (2013). Procurement Management and Administration in Organizations. HBJFCX Ltd: New York.

[44] Limberakis, C. G., (2012). Drilling for success in contract management, addressing CLM in upstream Oil \& Gas. 